\title{
Thyroglossal cyst and midline ectopic thyroid - a lesson to learn
}

\section{Abstract}

We are reporting a rare case of midline ectopic thyroid in a 10year old male child presented with complaint of midline neck swelling and history of recent increase in size. A clinical diagnosis of Thyroglossal cyst was made in view of typical location and clinical examination. On ultra sonography and FNAC, midline swelling was ectopic thyroid tissue with normal thyroid gland absent from its usual location. Computed tomography confirmed ultra sonographic findings.
Volume 6 Issue 2 - 2017

\author{
Kamal N Rattan,' Sandeep Kala, ${ }^{2}$ Priya Malik $^{3}$ \\ 'Department of Paediatric Surgery PGIMS, India \\ ${ }^{2}$ Department of General Surgery PGIMS, India \\ ${ }^{3}$ Department of Otolaryngology PGIMS, India
}

\begin{abstract}
Correspondence: Priya Malik Senior Resident Department of Paediatric Surgery General Surgery Otolaryngology Pt B D S Post Graduate Institute of Medical Sciences Rohtak I2400I R No 21 I Girls Hostel PGIM0053 Haryana, India, Email drpriyamalik09@gmail.com
\end{abstract}

Received: November 25, 2016 | Published: February 24, 2017

\section{Introduction}

Ectopic thyroid tissue is a rare developmental abnormality involving aberrant embryogenesis of the thyroid gland during its passage from the floor of the primitive foregut to its final pre-tracheal position i.e. anterior neck region between the second and fourth tracheal cartilages and accounting for $48-61 \%$ of the cases of thyroid dysgenesis. ${ }^{1}$ However, exact incidence of ectopic thyroid with absent thyroid gland is not known but prevalence of ectopic thyroid alone is about 1 per 100000-300000 people, increasing to 1 per $4000-8000$ patients with thyroid disease. ${ }^{2}$ Ectopic thyroid is more common in young females, especially in populations of Asian origin. Lingual thyroid is the most common accounting for $90 \%$ of cases, while sublingual types are less frequently encountered. The sublingual types may be suprahyoid, infrahyoid or at the level of the hyoid bone. ${ }^{3}$ Ectopic thyroid in the Thyroglossal cyst is second most common site..$^{4,5}$

\section{Case report}

A 10-year-old male child presented to our department with history of midline neck swelling present for one year. There was no history of compressive symptoms such as dysphagia, dyspnea, dysphonia, recurrent respiratory tract infections and neither there was history suggestive of hypothyroidism or thyrotoxicosis. General physical examination appeared to be normal. A midline non-tender neck swelling of size $2.5 \times 1.5 \mathrm{~cm}$ was present in sub hyoid region with smooth margins and firm consistency Figure1. Swelling was moving with swallowing and protrusion of tongue. Clinical diagnosis of Thyroglossal cyst was made. Haematological investigations were as follows; $\mathrm{Hb}-11 \mathrm{gm} \%$, Bleeding time-2'10 sec, Clotting time- 4'20", TLC $8,000 / \mathrm{cmm}$. Urine examination was normal. TSH was $6.0 \mathrm{mU} /$ $\mathrm{ml}$ while $\mathrm{T} 3$ and T4 were 1.2 and $42 \mathrm{nmol} / 1$ respectively. Ultrasound neck showed a heteroechoic lesion of size $2.3 \times 1.5 \mathrm{~cm}$ in sub hyoid region with flow on colour Doppler and was moving with deglutition and no normal thyroid gland at usual location. Fine niddle aspiration cytology was done showing features suggestive of hyperplasic change in Thyroglossal cyst or colloid cyst. Computed tomography was done which confirmed findings of ultrasound Figure 2. Patient was started on thyroxin. Radioisotope scan was not done due to age of patient. Patient has done well in follow up with normal thyroid profile.

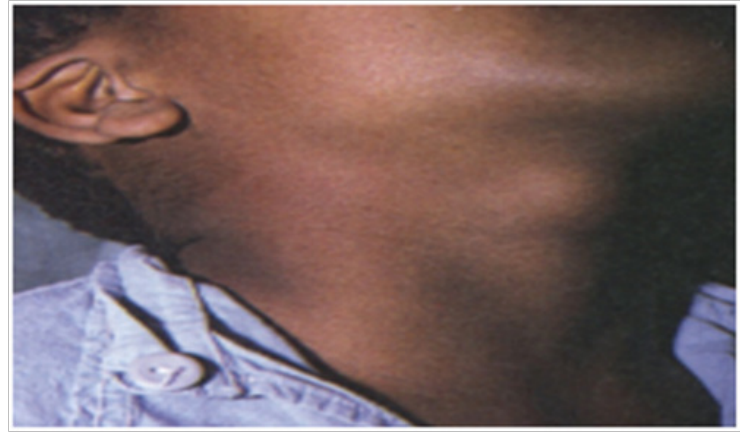

Figure I A midline non-tender neck swelling of size $2.5 \times 1.5 \mathrm{~cm}$ was present in sub hyoid region with smooth margins and firm consistency.

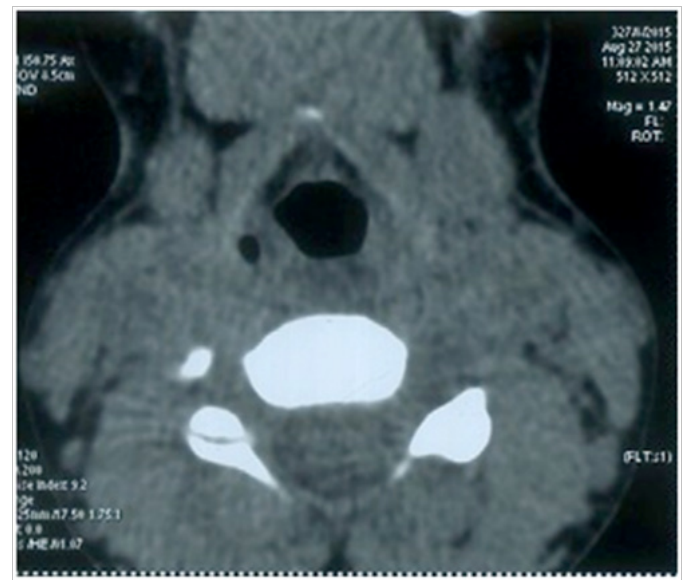

Figure 2 Fine niddle aspiration cytology was done showing features suggestive of hyperplasic change in Thyroglossal cyst or colloid cyst. Computed tomography was done which confirmed findings of ultrasound.

\section{Discussion}

Exact incidence of ectopic thyroid with absent thyroid gland is not known but ectopic thyroid is most commonly present as in lingual region. The wall of a Thyroglossal duct cyst is the second most common site for ectopic thyroid tissue accounting for $1-2 \%$ cases of 
ectopic thyroid. Ectopic thyroid is usually asymptomatic. One third of patients usually present with hypothyroidism, but hyperthyroidism is exceptionally rare ${ }^{6}$ Complications in ectopic thyroid are dysphagia, dysphonia, dyspnoea and haemorrhage. Large masses can present with airway obstruction and stridor in children. ${ }^{7,8}$ Sleep apnoea and respiratory obstruction in adult patients with lingual thyroid have been reported. ${ }^{9}$ It should be differentiated from Thyroglossal duct cyst, epidermal cyst, lymphadenopathy, lipoma, lymphangioma, sebaceous cyst, cystic hygroma, dermoid cyst, midline bronchial cyst and neoplasms. ${ }^{10}$ Surgical intervention is indicated when severe obstructive symptoms, bleeding, ulceration, cystic degeneration and malignancy occur. ${ }^{11}$ Our case presented with a clinical diagnosis of Thyroglossal cyst and was planned for surgery. This inadvertent removal of only functioning thyroid tissue would have rendered patient as permanent hypothyroid. So, proper clinical evaluation of midline swelling and routine use of preoperative ultra sonography is proposed for midline neck swelling to prevent such an avoidable error.

\section{Conclusion}

Though rare, ectopic thyroid should be kept in mind in as a rare differential diagnosis in midline neck swellings. Proper clinical evaluation and radiological investigations should be done before planning any surgical invention as it may be only thyroid tissue present in ectopic location and unnecessary surgery may render patient as permanent hypothyroid. It is to advice the upcoming surgeons to avoid a big mistake, just not to deal only clinically but to get all tests done to avoid removing only thyroid of patient and render him morbid for life.

\section{Acknowledgments}

None.

\section{Conflicts of interest}

Author declares there are no conflicts of interest.

\section{Funding}

None.

\section{References}

1. De Felice M, Di Lauro R. Thyroid Development and its disorders: Genetics and molecular mechanisms. Endocr Rev. 2004;25(5):722-746.

2. Gopal RA, Acharya SV, Bandgar T, et al. Clinical profile of ectopic thyroid in Asian Indians: a single-center experience. Endocr Pract. 2009;15(4):322-325.

3. Batsakis JG, El-Naggar AK, Luna MA. Thyroid gland ectopias. Ann Otol Rhinol Laryngol. 1996;105(12):996-1000.

4. Radkowski D, Arnold J, Healy GB, et al. Thyroglossal duct remnants. Preoperative evaluation and management. Arch Otolaryngol Head Neck Surg. 1991;117(12):1378-1381.

5. DeMello DE, Lima JA, Liapis H. Midline cervical cysts in children. Thyroglossal anomalies. Arch Otolaryngol Head Neck Surg. $1987 ; 113(4): 418-420$

6. Al-Jurayyan NA, el-Desouki MI. Transient iodine organification defect in infants with ectopic thyroid glands. Clin Nucl Med. 1997;22(1):13-16.

7. Dossing H, Jorgensen KE, Jorgensen EO, et al. Recurrent pregnancyrelated upper airway obstruction caused by intratracheal ectopic thyroid tissue. Thyroid. 1999;9(9):955-958.

8. Rahbar R, Yoon MJ, Connolly LP, et al. Lingual thyroid in children: a rare clinical entity. Laryngoscope. 2008;118(7):1174-1179.

9. Barnes TW, Olsen KD, Morgenthaler . Obstructive lingual thyroid causing sleep apnoea: a case report and review of the literature. Sleep Med. 2004;5(6):605-607.

10. Mussak EN, Kacker A. Surgical and medical management of midline ectopic thyroid. Otolaryngol Head Neck Surg. 2007;136(6):870-872.

11. Talwan N, Mohan S, Ravi B, et al. Lithium-induced enlargement of a lingual thyroid. Singapore Med J. 2008;49(3):254-255. 